\title{
Unleash the Unknown - Frontal Sinus and Nasal Septal Patterns in Personal Identification
}

\author{
Sudhakara Reddy, Rajesh N*, Raghavendra M N, Satish Alapati, Pavani kotha \\ Department of oral medicine \& radiology, Vishnu dental college, Bhimavaram, India \\ *Corresponding author: rajeshcap09@gmail.com
}

Received November 01, 2014; Revised November 13, 2014; Accepted November 17, 2014

\begin{abstract}
Purpose: This study was performed to evaluate the uniqueness and reliability of the frontal sinus and nasal septum by comparing various patterns of both the structures as observed on Posteroanterior cephalogram for personal identification. Materials and Methods: The present study comprised of 52 subjects (29 males and 23 females). Digital posteroanterior cephalogram radiographs were taken and frontal sinus and nasal septal patterns were analyzed for morphometric analysis using digora software version 2.7.103.437 network client copyright@ 1983 -2010 soredex, Finland. Results: Statistically significant difference was found for mean total number of loculations in frontal sinus between males and females and no statistical significance was found for nasal septal patterns. Conclusion: Within its limitations, the present study aimed to establish a simple, reliable means which aids in personal identification. Postero anterior cephalograms used in the present study have succeeded to some extent to establish a fact that there exists a variation in the arrangement of frontal sinus and nasal septum pattern and these features are unique to every individual and ultimately this can aid in human identification. Nevertheless, further studies are warranted to make it more reliable and ultimately benefiting the mankind.
\end{abstract}

Keywords: frontal sinus, nasal septum, posteroanterior cephalogram, digital

Cite This Article: Sudhakara Reddy, Rajesh N, Raghavendra M N, Satish Alapati, and Pavani kotha, "Unleash the Unknown - Frontal Sinus and Nasal Septal Patterns in Personal Identification." International Journal of Dental Sciences and Research, vol. 2, no. 6 (2014): 141-145. doi: 10.12691/ijdsr-2-6-5.

\section{Introduction}

Human identification is a most personified field which serves the mankind in different ways. Let it be a judicial matter or an emotional touch, identification of the loved ones will definitely render a Godly service and touches the hearts of many people. Most commonly employed means of identification include fingerprints, dental comparisons, and biological methods such as DNA profiling [1]. However, when soft tissue of human remains become putrid or is burnt, or DNA is severely degraded, fingerprint identification and DNA analysis are difficult to be carried out, and identity of remains in such conditions will not be a cake walk. So, preserving the ante-mortem and correlating them with the post-mortem records will render a useful aid in identification of a person or an individual. We, being the oral radiologists has to explore the paths which are beneficial to mankind. At this juncture, radiographs play a pivotal role and commonly accepted as a key tool in personal in identification process [1,2,3]. Added to it, radiographs are simple, cost effective and feasible method.

Radiographic examination of skeletal structures either in human remains or in living persons is a potentially useful procedure for personal identification and their radiographic comparisons were especially helpful for positive identification. The previously documented literature reports on practical use of skull radiographs for identification, such as vascular groove patterns, sella turcica, frontal sinus, mastoid processes and sinus. [1] Evidence based reports suggest that few studies have documented the use of frontal sinus and very few other studies have reported use of nasal septum pattern as an aid in personal identification. A combined use of frontal sinus and nasal septum patterns may be more useful for identification, giving further individual variations, since both are easily identifiable on a radiograph.

Frontal sinuses are nothing but air filled cavities which develop with that of age. These cavities become evident radiologically at the age of five or six years and develop to full extent by the age of 20 years [3]. These frontal sinuses are unique and definitely shows variations from person to person. Previous studies had disclosed that the frontal sinuses were found to be different for every individual even in case of monozygotic twins and dizygotic twins and implicit that they have individual morphological variations $[3,5,7,9]$. Configuration of frontal sinus is also said to be controlled by various environmental factors, although gender, race, and disease are known to affect its development $[13,14,15]$. On the other hand, nasal septal patterns also holds similar unique findings as does the frontal sinuses [13,14,15].

With this background, our study was undertaken to examine the variations in frontal sinus and nasal septum patterns as observed on a posteroanterior (PA) cephalogram, 
and to propose possible use of the same in personal identification.

\section{Materials and Methods}

An observational study was carried out in the department of Oral medicine, Oral diagnostics and Oral Radiology at a dental school in India. A total of 52 individuals consisting of 29 males and 23 females, with age ranging from 25 to 40 years visiting outpatient department were enrolled in the study. The participants in the present study include subjects without any history of bone dystrophies, non-traumatic and traumatic fractures, diabetes, and developmental anomalies affecting the jaw or syndromes of craniofacial structures. Digital Posteroanterior Cephalograms were obtained from the study participants using machine (Orthoralix) and PSP sensors (Digora), under standard exposure conditions as recommended by the manufacturer. The final images were obtained by accompanying software (Digora for Windows 2.7.103.437 network client, copyright (C) 1993-2010 Soredex) in Digital Imaging and Communications in Medicine (DICOM) format.

The radiographs thus obtained were subjected to analysis for frontal sinus and nasal septum patterns. Frontal sinuses were analyzed for symmetry as right or left dominant asymmetry, unilateral (right or left) or bilateral aplasia, presence of partial septa, presence of outline of upper border and total number of loculations.

Symmetry was assessed by measuring greatest horizontal dimension from midline septum on the either side and difference in right and left side dimensions was divided by greatest dimension and multiplied by 100 . If the percentage obtained was greater than $20 \%$ it was classified as asymmetrical (Tanuguchi et al criteria)

Nasal septum was classified according to direction of deviation of septum as straight, simple deviation to right or left side, sigmoid type, reverse sigmoid type, and others. (Tanuguchi et al criteria). The data obtained was subjected

to statistical analysis for testing significance of parameters using Mann Whitney test.

\section{Results}

Total of 52 subjects were examined for frontal sinus pattern variations (Table 1). Outline of upper border was absent in one individual, partial septa were absent in 16 individuals (Figure 1), 5 individuals had left partial septa (Figure 2), 2 had right partial septa and 29 had both right and left partial septa (Figure 3). Only 4 had left frontal sinus implicating unilateral aplasia (Figure 4). Midline septa absent in 1 individual, left dominant asymmetry (Figure 5) were noticed in 23 individuals and right dominant asymmetry was noticed in 15individuals. Whereas symmetrical frontal sinuses were present in 14 individuals. Comparison of loculations (Graph 1) denotes significant difference with mean loculations total both on leftand right side was found in males compared to females and difference between them wasfound to be statistically significant $(\mathrm{P}<0.01)$. Higher mean loculations-total was found in males compared to females and the difference between them was found to be statistically significant $(\mathrm{P}<0.01)$. Higher mean loculations-left was found in males compared to females and the difference between them was found to be statistically significant $(\mathrm{P}<0.01)$. Higher mean loculations-right was found in males compared to females and the difference between them was found to be statistically significant $(\mathrm{P}<0.05)$. (Table 4$)$. Nasal septum pattern was straight in 48 , left deviated in 3 and right deviated in 1 individual (Table 3).

Table 1. denotes sex distribution of total sample

\begin{tabular}{|c|c|c|}
\hline Gender & $\mathbf{n}$ & $\mathbf{\%}$ \\
\hline Male & 29 & $56 \%$ \\
\hline Female & 23 & $44 \%$ \\
\hline Total & $\mathbf{5 2}$ & $\mathbf{1 0 0 \%}$ \\
\hline
\end{tabular}

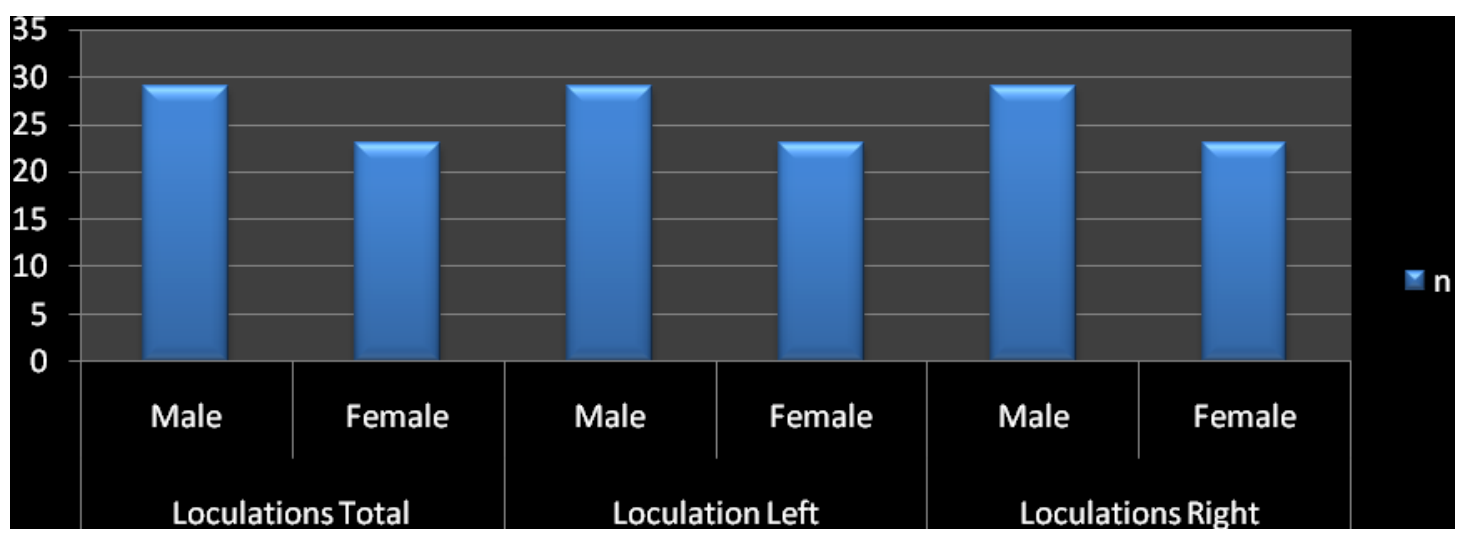

Graph 1. denotes significant difference with mean loculations total both on left and right side was found in males compared to females which was statistically significant

Table 2.

\begin{tabular}{|c|c|c|c|c|c|c|c|}
\hline \multirow{2}{*}{ Asymmetry } & \multicolumn{2}{|c|}{ Male } & \multicolumn{2}{|c|}{ Female } & \multirow{2}{*}{ Total } & \multirow{2}{*}{$\chi^{2}$} & \multirow{2}{*}{ P-Value } \\
\hline & $\mathbf{n}$ & $\%$ & $\mathbf{n}$ & $\%$ & & & \\
\hline Present & 19 & $66 \%$ & 18 & $78 \%$ & 37 (71\%) & \multirow{3}{*}{1.015} & \multirow{3}{*}{0.314} \\
\hline Absent & 10 & $34 \%$ & 5 & $22 \%$ & $15(29 \%)$ & & \\
\hline Total & 29 & $100 \%$ & 23 & $100 \%$ & 52 & & \\
\hline
\end{tabular}

No significant association between asymmetry and gender $(\mathrm{P}>0.05)$. 
Table 3.

\begin{tabular}{|c|c|c|c|c|c|}
\hline \multirow{2}{*}{ Nasal Septum } & \multicolumn{2}{|c|}{ Male } & \multicolumn{2}{|c|}{ Female } & \multirow{2}{*}{ Total } \\
\hline & $\mathbf{n}$ & $\%$ & $\mathbf{n}$ & $\%$ & \\
\hline Straight & 28 & $97 \%$ & 20 & $87 \%$ & 48 \\
\hline Left Deviate & 1 & $3 \%$ & 2 & $9 \%$ & 3 \\
\hline Right Deviate & 0 & $0 \%$ & 1 & $4 \%$ & 1 \\
\hline Total & 29 & $100 \%$ & 23 & $100 \%$ & 52 \\
\hline
\end{tabular}

Table 4. Comparison of loculation (Mann-Whitney test)

\begin{tabular}{|c|c|c|c|c|c|c|c|c|}
\hline Loculation & Gender & $\mathbf{n}$ & Mean & Std dev & SE of Mean & Mean difference & $\mathbf{Z}$ & P-Value \\
\hline \multirow{2}{*}{$\begin{array}{c}\text { Loculations } \\
\text { Total }\end{array}$} & Male & 29 & 3.79 & 1.45 & 0.27 & \multirow{2}{*}{1.141} & \multirow{2}{*}{-2.888} & \multirow{2}{*}{$0.004^{*}$} \\
\hline & Female & 23 & 2.65 & 1.23 & 0.26 & & & \\
\hline \multirow{2}{*}{$\begin{array}{l}\text { Loculation } \\
\text { Left }\end{array}$} & Male & 29 & 1.93 & 0.75 & 0.14 & \multirow{2}{*}{0.583} & \multirow{2}{*}{-2.991} & \multirow{2}{*}{$0.003 *$} \\
\hline & Female & 23 & 1.35 & 0.57 & 0.12 & & & \\
\hline \multirow{2}{*}{$\begin{array}{c}\text { Loculations } \\
\text { Right }\end{array}$} & Male & 29 & 1.86 & 0.95 & 0.18 & \multirow{2}{*}{0.558} & \multirow{2}{*}{-2.300} & \multirow{2}{*}{$0.021 *$} \\
\hline & Female & 23 & 1.30 & 0.76 & 0.16 & & & \\
\hline
\end{tabular}

*denotes significant difference

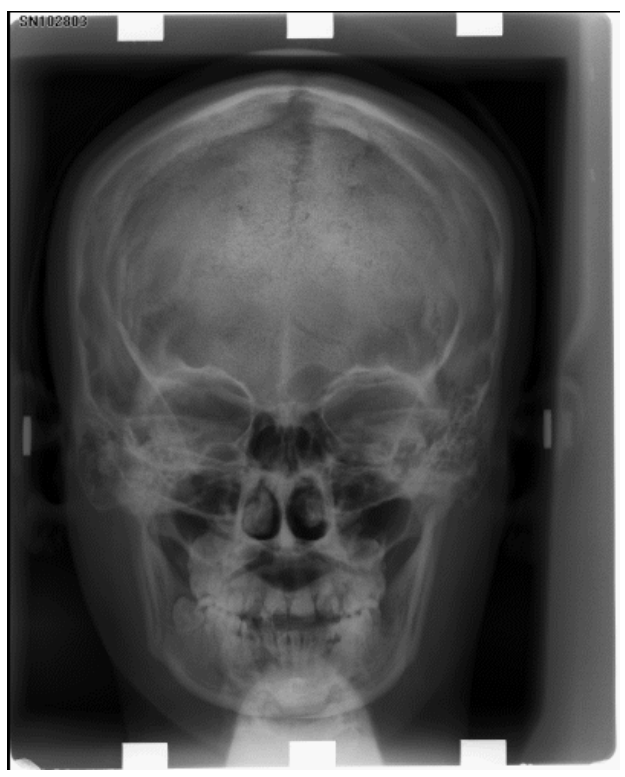

Figure 1. showing absence of partial septae and with unilateral aplasia or absence of frontal sinus

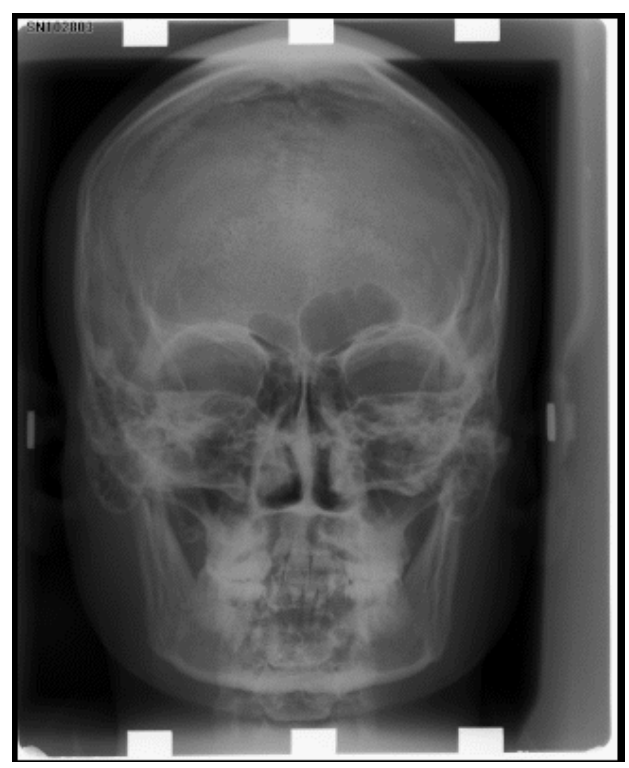

Figure 2. showing absence of partial septae in right frontal sinus

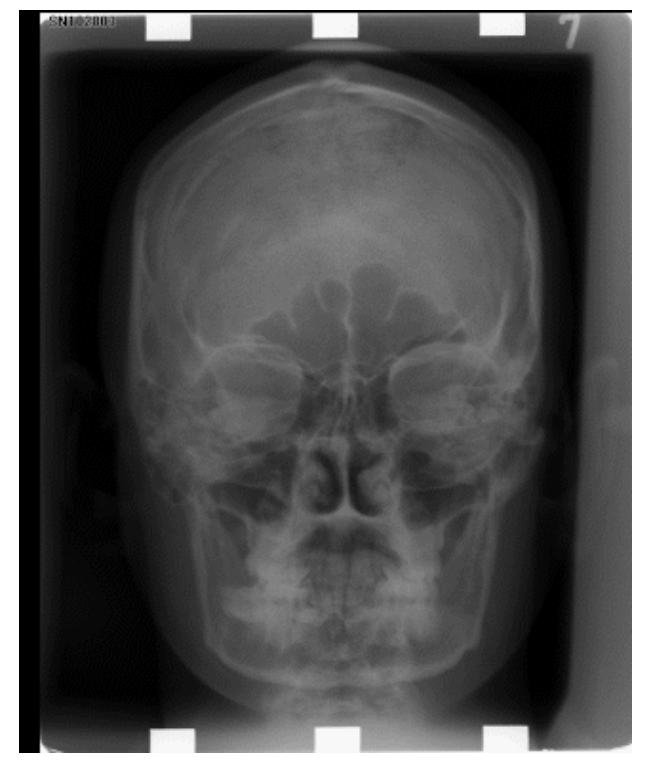

Figure 3. showing presence of partial septae in both left and right frontal sinus

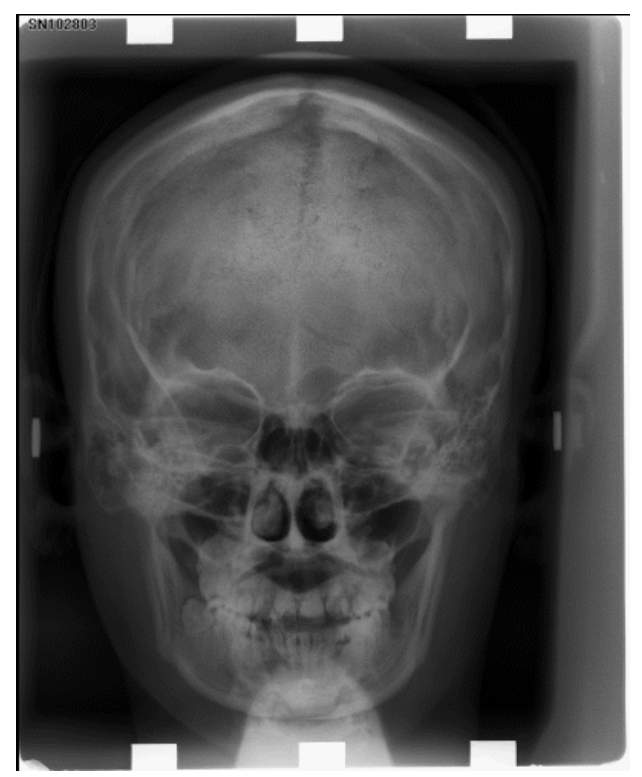

Figure 4. showing unilateral aplasia or absence of frontal sinus on right side 


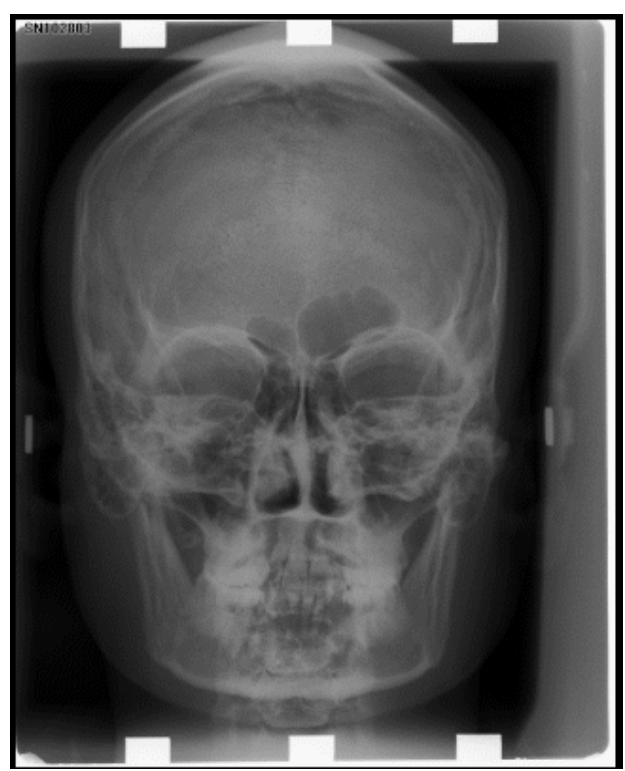

Figure 5. showing left dominant asymmetry

\section{Discussion}

Identification of persons using radiographs is found to be one of the most reliable and quick means. Comparison of skeletal structures, by superimposing ante-mortem and post-mortem records is very useful for positive identification [13,14]. However, no practical population data is available for a systematic identification procedure. So preservation of previously obtained radiographs will definitely overcome these obstacles. Radiographs of frontal sinuses are successfully used in today's forensic medicine for verification of personal identity. In these cases reaching an ante mortem radiograph of a person is essential [4].

Development of the frontal sinus and nasal septum usually completes by about 18-20 years of age. The frontal sinus has an anatomically special characteristic configuration, showing considerable individual differences [15]. Although nasal septum also shows individual variations, no population data are available. Frontal sinus patterns can significantly differ depending on the position of head in radiographic examination. However, horizontal diameter of frontal sinus shows very little variance due to flat configuration of sinuses, and it may also be the case for horizontal deviation of nasal septum to left or right. Therefore, a combined use of frontal sinus and nasal septum patterns may be practical for identification by comparison of ante- and post-mortem frontal skull radiographs.

In the present study, asymmetry of frontal sinus is seen in $71 \%$ of sample whereas symmetry in $29 \%$ of sample which is in contradictory to the observations made by David and Saxena et al who reported asymmetry and symmetry in 32\% and 58\% respectively and this can be attributed to the fact that there might be variation in craniofacial configuration, thickness of frontal bone and growth hormone levels. It was shown that a combined use of the nasal septum deviation (straight, simple deviation to the left or right, sigmoid, reverse sigmoid and other rare types) and the frontal sinus pattern (symmetry, left or right dominant asymmetry in combination with the number of lobulations) achieved different types of variations with varied incidences up to 5\%. This finding suggests that this classification has a high efficacy for exclusion (more than 95\% probability), suggesting possible usefulness to establish a systematic identification procedure.

In the present study nasal septum is present in $92.3 \%$ of individuals which is in contrast to studies done by Taniguchi et al and David et al who showed straight nasal septum in $13.4 \%$ and $22 \%$ respectively. This variation may be due to changes in the climatic conditions and genetic factors.

In addition, nasal septum and frontal sinus patterns were useful to establish identity in two forensic autopsy cases, showing no ante- or post-mortem changes, which may often be observed in dental findings [12].

The results witnessed in the present study suggests that a combined use of the nasal septum and frontal sinus patterns using postero anterior skull radiograph will be of quite useful tool and an easy, quick method for a tentative screening in case of mass disasters. Nevertheless, preservation of ante mortem radiographs is of utmost importance in identification process.

\section{Conclusion}

Person identification through radiographs is a rich area for development of new understandings and promising paths. The challenges, the mankind faces demands that we continuously seek inventory methods of creative thinking to unleash the hidden treasures to serve the human race. The present study had explored and witnessed a possible useful tool of frontal sinus and nasal septum patterns which aids in person identification. Postero anterior frontal skull radiographs have proven to be a potential valid tool in person identification. Nevertheless, only by continuing to conduct research on its many facets will be able to ensure its validity and reliability to meet the needs of the future mankind.

\section{References}

[1] Mari Taniguchi, Shigeki Sakoda, Tetsuya Kano, Bao-Liu Zhu, Yasunobu Kamikodai, Masaki Q. Fujita, Hitoshi Maeda. Possible use of nasal septum and frontal sinus patterns to radiographic identification of unknown human remains. Osaka city med. J., 2003; 49, 31-38.

[2] Nigel J. Kirk, Robert E. Wood, Marc Goldstein. Skeletal Identification using the frontal sinus region: A Retrospective Study of 39 Cases. Journal of forensic sciences, 2002; 47(2): 318323.

[3] Maria Priscilla David and Runjhun Saxena. Use of frontal sinus and nasal septum patterns as an aid in personal identification: A digital radiographic pilot study. J Forensic Dent Sci. 2010 Jul-Dec; 2(2): 77-80.

[4] Tatlisumak Ertugrul, Yilmaz Gulgun, Aslan Asim, Asirdizer Mahmut, Zeyfeoglu Yildiray, Tarhan Serdar. Identification of unknown bodies by using CT images of frontal sinus. Forensic Science International, 2007; 166 (1): 42-8.

[5] Cristiane Regina Ruiz, Nader Wafae. Anatomo-radiological and morphometrical study of the frontal sinus in humans. Braz. J. morphol. Sci. (2004) 21(1), 53-56.

[6] Quatrehomme G, Fronty P, Sapanet M, Grevin G, BailetO,Ollier A (1996) Identification by frontal sinus pattern in forensic anthropology. Forensic Sci. Int. 83, 147-153.

[7] Rouviére H (1948) Anatomie Humaine, Descriptive etTopographique. 6 th edn. Masson: Paris.

[8] Schaeffer JP (1942) Morris' Human Anatomy - A Complete Systematic Treatise. 10th edn. Blakiston Company: London. 
[9] Howie TO. Identical deformities in the nasal septum of a pair of identical twins. Br Med J.1946: 760-1.

[10] Grymer LF, Pallisgaard C, Melsen B. The nasal septum in relation to the development of the nasomaxillary complex: A study in identical twins. Laryngoscope. 1991; 101: 863-8.

[11] Grymer LF, Melsen B. The morphology of the nasal septum in identical twins. Laryngoscope. 1989; 99:642-646.

[12] Taniguchi M, Sakoda S, Kano T, Zhu BL, Kamikodai Y, Fujita MQ, et al. Possible use of nasal septum and frontal sinus patterns to radiographic identification of unknown human remains. Osaka City Med J. 2003; 49: 31-8.

[13] Pondé JM, Andrade RN, Via JM, Metzger P, Teles AC. Anatomical variations of the frontal sinus. Int J Morphol. 2008; 26 : 803-8.

[14] Porbonikova S. An x-ray investigation of the development of the frontal sinus in children. Folia Med (Plovdiv) 1974; 16: 213-20.

[15] Phrabhakaran N, Naidu M, Subramanian K. Anatomical variability of the frontal sinus and their application in Forensic identification. Clin Anat. 1999; 12: 16-9. 